\title{
An Alternative Approach: Teaching Evolution in a Natural History Museum Through the Topic of Vector-Borne Disease
}

\author{
Jane Pickering • Laura Fawcett • \\ Leonard Munstermann
}

Published online: 31 March 2012

(C) Springer Science+Business Media, LLC 2012

\begin{abstract}
Museums play a vitally important role in supporting both informal and formal education and are important venues for fostering public understanding of evolution. The Yale Peabody Museum has implemented significant education programs on evolution for many decades, mostly focused on the museum's extensive collections that represent the past and present tree of life. Twelve years ago, the Peabody began a series of new programs that explored biodiversity and evolution as it relates to human health. Modern evolutionary theory contributes significantly to our understanding of health and disease, and medical topics provide many excellent and relevant examples to explore evolutionary concepts. The Peabody developed a program on vector-borne diseases, specifically Lyme disease and West Nile virus, which have become endemic in the United States. Both of these diseases have complex transmission cycles involving an intricate interplay among the pathogen, host, and vector, each of which is subject to differing evolutionary pressures. Using these stories, the museum explored evolutionary concepts of adaptation (e.g., the evolution of blood feeding), coevolution (e.g., the "arms race" between host and vector), and variation and selection (e.g., antibiotic resistance) among others. The project included a temporary exhibition and the development of curriculum materials for middle and high school
\end{abstract}

J. Pickering $(\bowtie) \cdot$ L. Fawcett

Yale Peabody Museum of Natural History,

170 Whitney Ave,

New Haven, CT 06520, USA

e-mail: jane.pickering@yale.edu

\section{Munstermann}

Yale School of Public Health,

60 College Street,

New Haven, CT 06520, USA teachers and students. The popularity of the exhibit and some formal evaluation of student participants suggested that this educational approach has significant potential to engage wide audiences in evolutionary issues. In addition it demonstrated how natural history museums can incorporate evolution into a broad array of programs.

Keywords Evolution $\cdot$ Natural history museum $\cdot$ Vector-borne disease $\cdot \mathrm{K}-12$ education $\cdot$ Coevolution

\section{Introduction}

Evolution is the fundamental and unifying concept that explains the diversity of life on Earth. The National Science Education Standards (National Research Council 1996) deemed evolution an essential component of the science curriculum at all grade levels, and central to developing a scientifically literate public. This position is consistent with that of the National Academies, the American Association for the Advancement of Science, and many other scientific and educational organizations. However, despite many efforts, responses to questions about evolution by the U.S. public have remained largely unchanged in the last 25 years. For example, $43 \%$ of adults agree with the idea that humans developed from earlier species of animals (National Science Board 2008), and public understanding of evolutionary concepts is extremely poor (Gregory 2009). The well-publicized religious and cultural beliefs that influence people's acceptance of evolution are not the only forces that maintain the poor understanding of these concepts. Although natural history museum visitors are more likely than general poll respondents to accept evolution as an explanation for biological development and biodiversity, even among them, only a third 
demonstrate a basic grasp of Darwinian evolutionary principles, and almost all show some misconceptions about those principles (Diamond and Evans 2007). A series of museum visitor studies by E. Margaret Evans and her colleagues have shown that adults as well as children have persistent cognitive biases (e.g., that the world is stable and unchanging) that inhibit their understanding of evolutionary concepts. These biases require careful consideration when educational experiences are designed (Evans 2005, 2008; Spiegel et al. 2006; Evans et al. 2009; for detailed discussion of common misconceptions, see UC Berkeley's Understanding Evolution web site http://evolution.berkeley.edu/evolibrary/article/ 0_0_0/misconcep_01; Gregory 2009).

On average, Americans spend perhaps five percent of their lives in the classroom (Falk and Dierking 2010), and evidence is accumulating that people learn most science outside of the classroom (National Research Council 2009). In a 2008 survey, the majority of Americans (59 \%) had attended an informal science venue in the previous year, including $27 \%$ who visited a natural history museum (National Science Board 2010). Museums and other "science-rich" institutions recognized to play a vital role in supporting and improving formal K-12 education (e.g., Bevan 2007; Griffiths and Cahill 2009). Therefore these informal science institutions are important venues for fostering public understanding of evolutionary concepts (Diamond and Evans 2007; Diamond and Scotchmoor 2006; MacFadden et al. 2007). The current paper will describe how a traditional natural history museum, the Yale Peabody Museum of Natural History, has incorporated evolution education into its new programs even though they are not explicitly focused on evolution.

\section{A Home for Evolution}

Since the museum's first (unofficial) director, paleontologist Othniel Charles Marsh, curators at the Peabody Museum have been passionate advocates for Darwinian evolution. Indeed Marsh's discovery of toothed birds (Hesperornis and Ichthyornis) was hailed by Darwin himself as providing some of the most convincing support for his theory. However, it was not until the museum's current building opened in 1925 that the Peabody curators became engaged in a comprehensive effort to educate the public about evolution (for a detailed discussion of the following history, see Logan 2008). In January 1926, a few months after the Scopes trial in Dayton, Tennessee, the Peabody Museum opened with exhibits specifically designed to illustrate the processes and results of evolution, including those that led to humans. The first floor was (according to then director Richard Swann Lull) a circuit from the "beginning of the ascent of life and closing with its climax in the Hall of
Man." Lull deliberately laid out the museum galleries as a response to the uproar against teaching evolution in public schools and designed the exhibits so that they were able to provide a "visual proof" of human evolution. In 1925 Lull had published The Ways of Life, a comprehensive textbook of evolution directed at the general public. In its preface, he invited the public to seek in the halls of the Peabody Museum visual confirmation of what he described. Since that time, the Peabody Museum has developed numerous programs on evolution for K-12 students, their teachers, and the general public. Almost all have focused on the museum's extensive fossil collections that illustrate the pattern of life through Earth's history, as well as using the museum's extensive research and collections that relate to the study of the Tree of Life. However, in 2000, the museum began a series of new public programs that explored biodiversity and evolution as it relates to human health.

\section{Making Evolution Relevant}

A central difficulty in evolution education is that many of the "classic" examples found in textbooks and other outlets (e.g., Darwin's finches, peppered moths, the evolution of horses) seem irrelevant to everyday experiences of most people (Hillis 2007; Thanukos 2009). People learn more readily when concepts have direct relevance to daily life (Bransford et al. 2000). Linking K-12 curricula and classroom activities to current science and its practical applications, although challenging, has also been shown to increase student interest and motivation to learn (Bransford et al. 2000; Thanukos 2009). One way to make evolutionary concepts more concrete is through the use of medical examples. Modern evolutionary theory has contributed significantly to the understanding of health and disease. Evolutionary medicine (using the principles of evolution to study and treat human illness and disease) has become increasingly important to many areas of medical research and practice (Stearns et al. 2010). These topics provide many excellent examples to illustrate evolutionary concepts. Studies have shown that the majority of the adult public is more interested in medicine and new medical discoveries than other science and technology topics (NSB 2008), suggesting again that the use of current medical issues as a starting point for interpreting evolution is likely to be a successful strategy. Another advantage is that some medical topics (e.g., antibiotic resistance, evolution of the flu virus) are exemplars of rapid evolution, in which the changes occur within a human timescale of years or even months and therefore are easier for people to grasp readily. Unfortunately, during the broader discussion of these matters, the evolutionary bases for these changes are seldom expressed. For example, in 
coverage of antibiotic resistance, mass media and even biomedical researchers rarely use the word evolution to describe the processes leading to antibiotic resistance (Antonovics et al. 2007).

\section{The Impact of Vector-Borne Disease}

Nearly 20 years have passed since a blue-ribbon panel of the National Academy of Sciences issued a white paper that voiced concerns about the impending threat posed by global infectious disease (Lederberg et al. 1992). Since then the crisis of emerging infectious diseases, from HIV and the Ebola virus to multidrug resistant tuberculosis and MRSA, is regularly (and dramatically) covered in the news. Vectorborne diseases, which are transmitted by organisms (vectors) from one species to another, cause millions of deaths around the world each year and include malaria, dengue, yellow fever, and plague to name just a few. Global changes in climate, land use, water storage, and population size have made possible the emergence of new vector-borne diseases as well as the resurgence of old ones. Understanding emerging infectious disease requires the use of an evolutionary platform to explain the rapid emergence of novel hostparasite associations (Brooks and Holberg 2008), as well as providing opportunities to introduce concepts such as variation, inheritance, and selection (Thanukos 2008). Several projects have developed educational materials that use infectious disease examples to explore evolution (for example, see UC Berkeley's Understanding Evolution web site http://evolution.berkeley.edu/evolibrary/article/medicine_01 on the relevance of medicine to evolution, and the new $\mathrm{NIH}$ curriculum supplement Evolution and Medicine http://science. education.nih.gov/customers.nsf/HSEvolution.htm). In 2005 the Peabody Museum developed an educational project on "Biodiversity and Vector-Borne Disease". The educational goals for this initiative were to increase student and public understanding of biodiversity and vector-borne disease ecology.

The Peabody program has a specific focus on Lyme disease and West Nile virus. These infectious diseases have become endemic in many areas of the United States. Both are vector borne and are caused by pathogens transmitted to humans through the bite of a bloodsucking arthropod-a tick or mosquito. The pathogen for Lyme disease, the bacterium Borrelia burgdorferi, is transmitted by the Ixodes scapularis tick. The West Nile virus is transmitted by the bite of an infected Culex pipiens mosquito. These diseases have complicated transmission cycles that involve an intricate interplay among the pathogen, host and vector-each of which is subject to evolutionary pressures. Survival benefits and costs accrue to adaptive changes that result from selection pressures that over time have acted in a modified tug of war, where each component of the cycle must regularly adapt to the evolutionary changes in the others.

\section{Solving the Puzzle of Lyme Disease and West Nile Virus}

Natural history museum exhibits on evolution generally focus on how life changes through time and usually employ one of five themes: geological time, fossil assemblages, systematics, mechanisms of evolution, and historical approaches (Diamond and Scotchmoor 2006). However, evolutionary concepts can be integrated into most biologically and geologically themed exhibits (MacFadden et al. 2007). Medical examples are often used in exhibits on mechanisms of evolution, for example the evolution of the HIV virus in the University of Nebraska's Explore Evolution project (www.exploreevolution.org). At the Peabody Museum, an exhibit was developed whose primary theme concerned a medical topic (two vector-borne diseases) and then specifically incorporated Darwinian evolution into the narrative.

This temporary exhibit "Solving the Puzzle: Lyme Disease, West Nile Virus \& You" was opened in 2009. As part of the story, the impact of Darwin's work was placed in the context of vector-borne disease. Introduced by large and anatomically accurate models of a mosquito and tick, the exhibit detailed information on the disease puzzle that included the biology, transmission cycle, detection, and treatment. The exhibit explored the differences between viral and bacterial pathogens, time of arrival in Connecticut, and how the changing environment is influencing the incidence of both diseases. The installation of live mosquito and tick colonies allowed visitors to observe more closely the behaviors of these vectors.

The exhibit depicted how evolution by natural selection informs an understanding of the complex disease interactions, such as the coevolution of vector adaptations to counteract host defenses. Ticks were one of the earliest organisms to evolve blood feeding capabilities approximately 400 million years ago. Between 400 and 200 million years ago, vertebrates evolved mechanisms, such as blood coagulation, to stop the bleeding process. This led to a coevolutionary arms race between vectors and hosts in the feeding site. As a consequence, blood feeders evolved a wide set of molecules, such as anticoagulants, to inhibit host systems that prevent bleeding.

Another section of the exhibit dealt specifically with the evolution of blood feeding and explicitly developed the following themes: Mosquitoes and other blood feeders have existed for millions of years, and blood feeding has evolved independently in at least six different insect lines. The ability of insects to exploit the nutrient-rich resource of 
blood came about through several major adaptations, including mouthparts that are able to penetrate skin and remove host fluids, re-engineered digestive enzymes that act specifically on blood proteins, and behavior that includes a search pattern for suitable blood-containing organisms. The exhibit also illustrated that although the mechanism for withdrawing the blood may be similar in different insects, the associated mouthparts may have very different evolutionary origins. This showed how each part of a complicated structure has an associated evolutionary history.

Although no formal evaluation of the exhibit was conducted, informal interviews and anecdotal observations indicated that the exhibit was successful in conveying the evolutionary message. Students from Yale's School of Nursing were trained to deliver floor activities and answer visitor questions and were present in the exhibit each weekend. They discovered that visitors were particularly interested in certain subjects, some of which were directly related to increasing understanding of evolution. For example, visitors self-reported learning in areas such as how the life cycle of the pathogen intersects with the life cycle of the vector and how new viruses are emerging. One of the most intriguing floor activities to visitors, the demonstration of how random genetic mutations can create new flu strains, was also very intriguing to visitors. Overall, the exhibit was very popular with many people commenting to both the students and others (principally admissions and store staff) that they had enjoyed it and had obtained information about both the biology of these diseases and how that information was relevant in their own lives.

\section{A New Curriculum on Vector-Borne Disease}

The Biodiversity and Vector-Borne Disease initiative developed a curriculum module for students in grades five to ten that explored the differences in transmission, detection, and treatment of viral and bacterial diseases. The central theme was for students to design new outdoor recreation areas that will reduce public risk of contracting vector-borne diseases. The curriculum provided background information on the diseases and their vectors and included five inquiry-based hands-on classroom activities. These modules and associated materials were developed by program staff in concert with a core group of active middle school teachers (Peabody Fellows) in 2006-2007. These teachers piloted the science curriculum modules in each of their classrooms. In association with this curriculum, a BioAction Kit was assembled that contained scientific instruments, specimens and supplies relevant to each teaching module. In subsequent years, the curriculum modules were refined for further testing and dissemination to school districts across the United
States, and in 2010, it was made available for national release. For more details see http://peabody.yale.edu/teachers/ curricula.

The curriculum was carefully designed to support national and local science standards. National science standards advocate that the concepts of biological evolution be introduced at the middle school level (for a detailed discussion of evolution in the national standards, see Evans 2005). The Peabody Museum modules included concepts of diversity, adaptation, variation and selection-all recommended by national standards for coverage at the middle school level. Connecticut state standards that were addressed included the grade 8 standards on Heredity and Evolution as well as grade 10 standards in Genetics, Evolution and Biodiversity (http://www.sde.ct.gov/sde/cwp/view.asp?a=2618\&q= 320890). The purpose of the curriculum was to investigate Lyme and West Nile and understand the elaborate vectorhost-pathogen systems that maintain their distinct disease cycles.

Evolutionary forces drive all aspects of the vector-borne disease interactions. Each was specifically addressed in the curriculum's content-rich background sheets. "Evolving Alone... and Evolving Together" explored mutation, adaptation and coevolution, and "Bacteria Fight Back" explained selection dynamics in antibiotic resistance. Because the Lyme pathogen is a bacterium, it can be treated with antibiotics. It is not a likely candidate for the development of antibiotic resistance, however, because the ticks do not have the opportunity to return antibiotic-resistant mutant bacteria into the cycle of disease. This disease cycle was contrasted with case studies of antibiotic resistance in other cycles to compare mechanisms of resistance as evolutionary phenomena. Therefore the bacterial lesson in particular had an evolutionary focus more explicit than others.

The overall impact of the curriculum was evaluated intensively by qualitative and quantitative methods. The purpose of the student evaluation was to determine the impact of the overall project by assessing a broad range of concepts and information included in the curriculum. The evaluation was focused on the Connecticut participants but included assessments administered to a subset of students from a national dissemination site in Texas. Whereas many aspects of evolutionary thought were embedded in the curriculum (diversity, adaptation, coevolution, variation, selection), impact on student understanding of evolution (in isolation from other topics) was not specifically addressed in the qualitative data. Nonetheless, encouraging trends were present in the quantitative evaluations. The data were obtained as follows: a student evaluation instrument was modeled closely on state mastery tests and comprised 19 multiple choice items as well as an attitudinal survey. This instrument was administered twice to students, first as a preassessment at the beginning of the school year and 
Table 1 Average score for the students on the pre- and postassessment (data are provided from four Connecticut teacher cohorts, the combined Connecticut results, and one Texas teacher cohort)

\begin{tabular}{|c|c|c|c|c|c|c|c|c|}
\hline & \multicolumn{4}{|c|}{ Middle school student cohorts } & \multicolumn{4}{|c|}{ High school student cohorts } \\
\hline & $N$ & $\begin{array}{l}\text { Avg pretest } \\
\text { score }\end{array}$ & $\begin{array}{l}\text { Avg. posttest } \\
\text { score }\end{array}$ & $\begin{array}{l}P \text { of } \\
\text { difference }\end{array}$ & $N$ & $\begin{array}{l}\text { Avg pretest } \\
\text { score }\end{array}$ & $\begin{array}{l}\text { Avg posttest } \\
\text { score }\end{array}$ & $\begin{array}{l}P \text { of } \\
\text { difference }\end{array}$ \\
\hline CT fall/spring 2007-2008 & 561 & 0.25 & 0.45 & $<0.001$ & 272 & 0.27 & 0.39 & 0.001 \\
\hline CT fall 2008 & 158 & 0.30 & 0.75 & $<0.001$ & 273 & 0.29 & 0.48 & $<0.001$ \\
\hline CT spring 2009 & 332 & 0.31 & 0.41 & 0.003 & 302 & 0.27 & 0.41 & $<0.001$ \\
\hline CT spring 2010 & 233 & 0.22 & 0.39 & $<0.001$ & 190 & 0.34 & 0.43 & 0.059 \\
\hline CT total & 1,284 & 0.26 & 0.47 & $<0.001$ & 1,037 & 0.29 & 0.43 & $<0.001$ \\
\hline TX fall 2009 & 66 & 0.23 & 0.47 & $<0.001$ & 66 & 0.21 & 0.33 & 0.045 \\
\hline
\end{tabular}

again as a postassessment after being exposed to the Biodiversity and Vector-Borne Disease curriculum. The teachers scored the student work and reported the results to program staff. Pre- and postscores were compared to examine performance changes as a function of having completed the curriculum.

One of the assessment items, related to the bacterial lesson referenced above, addressed a specific evolutionary concept: the issue of how bacteria develop antibiotic resistance (i.e., the concepts of mutation and adaptation). Many students have the misconception that exposure to antibiotics directly causes bacteria to be resistant, rather than changing the relative frequencies of resistant vs. nonresistant individuals by killing off the latter (Gregory 2009). Table 1 shows the average score for the students on the pre- and postassessment for this item. Data are provided from four Connecticut teacher cohorts, the combined Connecticut results, and the one Texas teacher cohort.

Student postassessments were compared to their own preassessments using paired sample Student's $t$ tests, ${ }^{1}$. A statistically significant difference was the likelihood of the difference occurring by chance of less than five percent $(P<$ $0.05)$. In this case, three of the four groups evaluated demonstrated highly significant increases ( $P<0.001$ likelihood). The students were clearly able to answer the question about antibiotic resistance after the lessons were introduced and led to the conclusion that the program had a positive impact on student understanding and knowledge of the topic. Note that two of the high school cohorts did not show significant gains

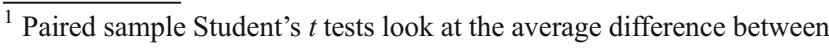
participants' scores on one measure and the same participants' scores on another measure. They are a more exact means of examining the difference between the measures than would be the case if all of the pretests were to be compared to the posttests without matching. As with all $t$ tests, they provide a means of determining the $p$ value (likelihood of the difference being due to chance) of the difference between the two measures.
}

in knowledge. In one case (CT spring 2010), the pretest results were very high, possibly because these students have been taught relevant evolutionary concepts in the grade 10 curriculum. An interpretation may be that although the students gained knowledge from the lesson, the preexisting knowledge base prepared them for thinking in an evolutionary context. The other case (TX fall 2010) is more difficult to explain. Because of the small sample size, classroom or individual teacher effects may have impacted the results.

\section{Conclusion}

The Peabody Museum, like many natural history museums, identifies evolution by natural selection as a central theme in its educational mission and overall interpretive strategy. The museum collections and exhibits illustrate the pattern of life throughout Earth's history, the mechanisms of biological evolution that have formed that pattern and how it has changed over time. Classic textbook examples used in teaching Darwinian evolution, such as the history of the horse and the relationship between dinosaurs and birds, have their roots in research done at the Peabody Museum. Whereas these evolution programs have focused on the history and present diversity of life, a broader range of programming is underway for exploring novel means to integrate the evolutionary story. The Biodiversity and VectorBorne Disease initiative provided an opportunity to pilot this approach through exhibits and the development of education curricula. By explicitly considering evolution during the development of these activities, visitors and K-12 students were engaged in a more personal approach that demonstrated the relevance and importance of Darwin's revolutionary concepts to everyday life.

Acknowledgments This project was supported by the National Center for Research Resources and the Division of Program Coordination, Planning, and Strategic Initiatives of the National Institutes of Health 
through Grant Number R25 RR20818. The authors thank the Biodiversity and Vector-Borne Disease program's evaluators SageFox Consulting (Alan Peterfreund \& Kenneth Rath) and Minda Borun. This contribution is dedicated to the memory of Terri Stern, education specialist, who developed many aspects of the Peabody Fellows Program.

\section{References}

Antonovics J, Abbate JL, Baker CH, Daley D, Hood ME, Jenkins CE, et al. Evolution by any other name: antibiotic resistance and avoidance of the E-word. PLoS Biol. 2007;5(2):137-40.

Bevan B. When schools meet museums: finding a third Way. ASTC Dimensions, 2007; pp 3-7.

Bransford JD, Brown AL, Cocking RR, editors. How people learn. Washington: National Academies Press; 2000. pp 374.

Brooks DR, Holberg EP. Darwin's necessary misfit and the sloshing bucket: the evolutionary biology of emerging infectious diseases. Evol Educ Outreach. 2008;1:2-9.

Diamond J, Evans EM. Museums teach evolution. Evolution. 2007;61 (6):1500-6.

Diamond J, Scotchmoor J. Exhibiting evolution. Mus Soc Issues. 2006;1(1):21-48.

Evans EM. Teaching and learning about evolution. In: Diamond J, editor. Virus and the whale: exploring evolution in creatures small and large. Arlington: National Science Teachers Association Press; 2005. p. 25-37.

Evans EM. Conceptual change and evolutionary biology: a developmental analysis. In: Vosniadou S, editor. International handbook of research on conceptual change. New York: Routledge; 2008. p. 263-94.

Evans EM, Spiegel AN, Gram W, Frazier BN, Tare M, Thompson S, et al. A conceptual guide to natural history museum visitors' understanding of evolution. J Res Sci Teach. 2009;47(3):326-53.
Falk JH, Dierking LD. The 95 percent solution. Am Sci. 2010;98 (6):486-93.

Gregory TR. Understanding natural selection: essential concepts and common misconceptions. Evol Educ Outreach. 2009;2:156-75.

Griffiths P, Cahill M. The opportunity equation: transforming mathematics and science education for citizenship and the global economy. New York: Carnegie Corporation of New York and Institute for Advanced Study; 2009. p. 63.

Hillis DM. Making evolution relevant and exciting to biology students. Evolution. 2007;61(6):1261-4.

Lederberg J, Shope RE, Oaks SC. Emerging infections: microbial threats to health in the united states. Washington: National Academies Press; 1992. p. 294.

Logan A. A museum of ideas: evolution education at the Peabody Museum in the 1920s. 2008. http://peabody.yale.edu/logan-essay. Accessed 6 March 2012.

MacFadden BJ, Dunckel BA, Ellis S, Dierking LD, Abraham-Silver L, Kisiel J, et al. Natural history museum visitors' understanding of evolution. Bioscience. 2007;57(10):875-82.

National Research Council (NRC). National science education standards. Washington: National Academies Press; 1996. p. 262.

National Research Council (NRC). Learning science in informal environments. Washington: National Academies Press; 2009. p. 336.

National Science Board. Science and engineering indicators 2008. Arlington, VA: National Science Foundation (NSB 08-01). 2008.

National Science Board. Science and engineering indicators 2010. Arlington, VA: National Science Foundation (NSB 10-01). 2010.

Spiegel AN, Evans EM, Gram W, Diamond J. Museum visitors' understanding of evolution. Mus Soc Issues. 2006;1:67-84.

Stearns SC, Nesse RM, Govindaraju DR, Ellison PT. Evolutionary perspectives on health and medicine. PNAS. 2010;107(1): 1691-5.

Thanukos A. Views from understanding evolution: parasites and pathogens take the leap. Evol Educ Outreach. 2008;1:25-8.

Thanukos A. From newsroom to classroom. Evol Educ Outreach. 2009;2:533-7. 